\title{
Public perceptions of forests across Italy: an exploratory national survey
}

\author{
Giuseppe Carrus ${ }^{(1)}$, \\ Angelo Panno (2), \\ Juan Ignacio Aragones ${ }^{(3)}$, \\ Marco Marchetti ${ }^{(4)}$, \\ Renzo Motta ${ }^{(5)}$, \\ Giustino Tonon ${ }^{(6)}$, \\ Giovanni Sanesi ${ }^{(7)}$
}

\begin{abstract}
In a context of progressive expansion of the Italian forest area, we present the results of a national survey exploring public perception of forests across different geographical scales in Italy. Perceptions of forests are assessed in relation to popular beliefs on relevant environmental issues such as countering climate change, protecting biodiversity, and promoting social cohesion and environmental education. Participants $(N=1059)$ living in five different regions of Northern (Trentino-Alto Adige/Suidtirol, Piemonte), Central (Lazio, Molise) and Southern Italy (Puglia), were recruited in the survey and completed a paperand-pencil questionnaire. Survey questions regarded the estimated percentage of forest cover, the perceived importance of different environmental issues and of different material and non-material forest products, as well as participants' perceptions regarding connectedness to nature. Results revealed a generalized tendency to overestimate the extension of forest surface area in the participants' region, in Italy, and in the European Union. Results also showed high scores for participants' perceived importance of environmental issues, such as climate change and biodiversity protection, and in their belief that forests could play a positive role in addressing these issues and providing important outcomes and benefits for the quality of human life, such as health and well-being or social cohesion.
\end{abstract}

\section{Keywords: Forest Perceptions, Nature Experience, Environmental Attitudes, Environmental Issues}

\section{Introduction}

Forests have been considered an important asset throughout human history for many reasons (Abel 1998, Perlin 1991). Of course, experts in ecological and forestry science would easily point to the crucial role of forests in ensuring ecosystem function in present-day habitats. However, public perceptions of forests is also an interesting topic of investigation for scholars in the environmental-psychological domain, in particular for those interested in exploring the interface between ecology and social science in terms of human response to the physical environment.

As forests and trees can also be considered a substitute for the concept of nature in naive thinking and common sense perceptions, when discussing general public perceptions and beliefs about forests it is important to highlight the fundamental role of natural settings in positively affecting human environmental preference and well-being. Indeed, the past three decades of research in environmental psychology (Van Den Berg et al. 2007), have consistently underscored the role of the physical environment for shaping the quality of life in contemporary society (Pol et al. 2017).

Generally speaking, the perceptive and evaluative mechanisms that drive human adaptation and evolution in the natural environment have been subject to consistent investigation by scholars in environmental
(1) Roma Tre University, Department of Education, Rome (Italy); (2) European University of Rome, Department of Human Science, Rome (Italy); (3) Complutense University of Madrid, Department of Psychology, Madrid (Spain); (4) University of Molise, Dipartimento di Bioscienze e Territorio (Italy); (5) University of Turin, Dipartimento di Scienze Agrarie, Forestali e Alimentari, Turin (Italy); (6) Libera Università di Bolzano, Facoltà di Scienze e Tecnologie, Bolzano (Italy); (7) University of Bari Aldo Moro, Department of Agro-environmental and Territorial Sciences, Bari (Italy)

@ Giuseppe Carrus (giuseppe.carrus@uniroma3.it)

Received: Mar 06, 2020 - Accepted: Jun 08, 2020

Citation: Carrus G, Panno A, Aragones JI, Marchetti M, Motta R, Tonon G, Sanesi G (2020). Public perceptions of forests across Italy: an exploratory national survey. iForest 13: 323-328. - doi: 10.3832/ifor3394-013 [online 2020-07-28]

Communicated by: Marco Borghetti psychology (see Mercado-Doménech et al. 2017 for a recent review). This entire body of research focuses on the positive role of exposure to nature for the promotion of health and well-being over an individual's lifespan (Hartig et al. 2011, Carrus et al. 2015a, 2015b, 2017, Panno et al. 2017).

Within this general theoretical framework, and given the positive role that forests and trees seem to have for the promotion of psychological restoration, it is indeed interesting to explore and deepen our understanding on what the general public perceptions and assessments of forests are and how these perceptions might be linked to people's general environmental attitudes and beliefs in relation to the environment, or to environmental issues such as global climate change and biodiversity. This issue is also linked to the more general theme of how citizens and socalled "civil society" might contribute to the worldwide goal of sustainable transitions in present-day democracies, i.e., understanding how the public perceives specific issues that have a direct impact on the quality of planetary ecosystems as well as on the quality of human life. This insight might thus be helpful in developing more effective strategies to drive such sustainable transitions (Frantzeskaki et al. 2016).

Currently, forests cover almost $40 \%$ of Italy's national territory (Italian Inventory of Land Use - IUTI 2017). Since 1990, it has increased to over 1 million ha, that is, an average of $800 \mathrm{~m}^{2}$ of new forests per minute. In 2018, for the first time in centuries, the 
national territory covered by forests exceeded that used for agricultural purposes (Marchetti et al. 2018).

In this article, we present the results of a survey aimed at assessing public perceptions of forests across different geographical and socio-economical scales in Italy. More specifically, we investigate how these perceptions of forests are related to popular beliefs on relevant environmental issues, such as the importance of countering climate change, protecting biodiversity, promoting social cohesion and enhancing environmental education.

A consistent number of studies in the field of environmental psychology have analyzed the so-called "social construction" of environmental issues, focusing in particular on the processes of generation and diffusion of the "environmental discourse" and the role that mass media play in these processes (Carrus et al. 2009, Graumann \& Kruse 1990,). At the basis of this research is the assumption of the often-mediated character that many environmental experiences hold for citizens in present-day societies. Thus, the environmental discourse in contemporary society reflects a change in our construction of the world we live in, where the role of mass media is fundamental in this process. In this way, the power of the media can be identified not so much in the simple and immediate documentation and dissemination of news, but rather in the relevant exchanges between journalists, commentators, experts and politicians (Graumann \& Kruse 1990). The media exert their influence through "agenda setting", that is, by directing public attention to specific issues (environmental and otherwise) on which citizens must take a position rather than to evaluations. Therefore, in relation to the environment and related issues, the information conveyed by the media seems to be more important than direct and subjective everyday experiences. This issue is also related to a cultural-specific construction of the environment. In fact, societies might differ in their representations of the environment and environmental risks, which could lead to individual experiences of the environment becoming largely dependent on these social construction processes.

In the discourse on forests, an example of these processes can be found in the recent case of the Amazon forest fires in 2019, where the issue of forests has certainly received extraordinary media coverage around the globe. Indeed, as reported by several mass media (e.g., https://www.lati mes.com/opinion/story/2019-09-06/amazon -rainforest-fire), the extensive burning of the Amazon forest during the summer of 2019 was a great shock and caused much concern around the globe, certainly raising public opinion's awareness of the importance of forests for human societies and ecosystems worldwide.

Starting from these socio-constructivist assumptions, it is important to ask our- selves two questions. First, whether (and how) public perceptions of relevant environmental elements, such as forests, correspond to actual facts and, second, how such public perceptions are linked to people's attitudes, opinions and beliefs about other relevant environmental phenomena, such as global climate change or biodiversity conservation.

In the last few decades, global environmental change has gained increasing relevance in scientific inquiry, for decision makers, and for the general public. This has led to a greater focus on the "human dimension" of phenomena such as climate change, biodiversity loss, or $\mathrm{CO}_{2}$ emissions. Likewise, an increasing consensus in the scientific community, the political arena, and public opinion has emerged on the need for the participation and support of local communities in order to achieve global goals such as emissions reduction, biodiversity conservation and more sustainable management of natural resources such as forests, green areas or natural reserves, in general.

Psychological research has attempted to study the relationship between people and forests with the aim of contributing to the management of large-scale natural spaces such as parks and protected areas in countries like the US (Heberlein 1989). In Italy, however, the relationship between people and different typologies of urban and periurban forests has only recently been the focus of social and behavioral sciences (Carrus et al. 2015b) that assess the restorative potential of green spaces on daily life experiences for the promotion of human well-being. Although forests are an increasing attraction for a large number of people, the accuracy of people's perception of forests at the national level is a rather unexplored issue for research in this field, with some notable exceptions (Roovers et al. 2002, Meijaard et al. 2013). This is due to widespread enhanced sustainable lifestyles among the general public and the greater quest among urban dwellers for positive experiences of psychological restoration in nature. Previous works have analyzed local stakeholders' perceptions of forests in specific areas (Pastorella et al. 2017, Paletto et al. 2018), but no study to our knowledge has developed an extensive survey covering the entire Italian territory.

Environmental psychology studies have shown with consistent empirical evidence that as human beings feel a part of nature, their degree of environmental concern increases. This relationship, which has systematically appeared in the psychological literature, has resulted in different approaches to study the concept of individual connection to nature in contemporary societies. As reviewed by Tam (2013), several constructs with related psychometric measures have been proposed to measure the degree of inclusion of the human self in "nature". Undoubtedly, the proposal that has gained more attention in this domain has been the concept of "Connectedness to Nature", defined by Mayer \& Frantz (2004) and measured through the Connectedness to Nature Scale (CNS). In another study, these authors showed that the direct experience of nature positively predicts subjective well-being in a group of people who participated in a nature tour, and that this relation is mediated by increases in connectedness to nature (Mayer et al. 2009). This empirical evidence has been demonstrated in other works reporting how people who walk on nature trails experience increased well-being and positive affection (Pasca et al. 2019). In a similar vein, the concept of Connectedness to Nature has been related to well-being, spirituality, and pro-environmental behavior in studies conducted in Mexico and France (Navarro et al. 2019). The results of these studies show that, in both countries, connectedness to nature favors spirituality and personal well-being (Pasca et al. 2019).

There is converging evidence suggesting that the concept of connectedness to nature could be incorporated in studies on human valuation and perception of the natural environment, as it appears linked not only to pro-environmental behaviors but also to subjective well-being experienced after exposure to natural settings. In the remaining sections of this paper, we present the results of a national survey conducted for the purpose of exploring the characteristics and accuracy of public perception of forests across Italy and their relation to attitudes and beliefs about other relevant environmental issues, such as climate change, biodiversity, and environmental education.

\section{Materials and methods}

\section{Survey data}

The survey data were collected on a convenience sample, using a paper-and-pencil questionnaire administered from (summer) 2016 to (springtime) 2017 by trained interviewers to a total of 1059 respondents living in five different regions of North, Central and South Italy: Trentino-Alto Adige/ Südtirol (19\%), Piemonte (19\%), Lazio (25\%), Molise (19\%), and Puglia (18\%). Respondents are urban (75\%) and rural (25\%) residents, a pattern that corresponds to the current distribution of the entire population according to ISTAT, the Italian National Statistical Institute (https://www.istat.it/it/ files/2019/12/Asi-2019.pdf), and are equally distributed for gender. Average age of the respondents is $46 \pm 18.25$ (SD) years. Tab. 1 shows the characteristics of the sample of survey respondents in detail. Respondents were ensured of the anonymous character of the survey, and made aware that the survey completion was entirely voluntary, so no specific ethics documentation needed to be signed by respondents.

The questionnaire employed for the survey contains the following:

1. A section assessing socio-demographic 
characteristics of the respondents (age, gender, residence, occupation, and level of education).

2. A section on the quantitative perception of forests consisting of the following items: (i) Individual estimates of the percentage of forest surface in the territory of Italy, participants' region, and the EU respectively. Answers range from 0 to $100 \%$. (ii) Individual estimates of forest efficacy in facing environmental issues (e.g., climate change; desertification; biodiversity protection; wood/cellulose/biomass production; and support for tourism). Answers range from " $1=$ not at all important" to " $5=$ very important". (iii) Individual estimates of the importance of different material and non-material forest products (i.e., firewood; construction wood; biomass/cellulose; wild berries/ mushrooms/fruits; medicines and nutraceuticals; health and well-being; social cohesion and sense of community; and environmental education). Answers range from " $1=$ not at all important" to " 5 = very important". (iv) Two items on the need for human intervention in forest management ("It is necessary that human beings take care of forests"; "Forests must be left free from human interference"). Answers range from " $1=$ completely disagree" to " $5=$ completely agree".

3. A section on Connectedness to Nature composed of four items taken from the CNS by Mayer \& Frantz (2004), adapted and translated into Italian by the authors. Answers range from " $1=$ completely disagree" to " 5 = completely agree".

\section{Statistical analysis}

Descriptive statistics, ANOVA models and bivariate correlations were computed using the SPSS ${ }^{\oplus}$ software (IBM Corp., Armonk, NY, USA), to explore the main trends in the variables measured (descriptive statistics), the main patterns of relations among the variables measured in our questionnaire (bivariate correlations) and the existence of group differences in the main variables measured as a function of participants' socio-demographic characteristics and geographical context.

\section{Results}

General trends and descriptive statistics

First, we looked at the descriptive statistics and the relations among the main variables assessed in the survey.

Tab. 2 shows the descriptive statistics for the main variables measured in the survey. Gender is equally balanced across the participants, and the level of education is in line with the Italian national pattern.

\section{Connectedness to nature}

We assessed differences in Connectedness to Nature as a function of participants' characteristics (e.g., geographical context). Fig. 1 and Fig. 2 show the average
Tab. 1 - Characteristics of the sample of survey respondents.

\begin{tabular}{llc}
\hline Characteristic & Class & Perc. (\%) \\
\hline Sex & Women & 50.4 \\
\cline { 2 - 3 } Education Level & Men & 49.6 \\
& Primary or secondary school & 17.1 \\
\cline { 2 - 3 } & High school & 51.1 \\
\cline { 2 - 3 } & Bachelor's or Master's degree & 24.3 \\
\cline { 2 - 3 } Marital Status & Doctorate degree/Specialization & 7.5 \\
\hline & Single & 31.9 \\
\cline { 2 - 3 } & Married & 49.1 \\
\cline { 2 - 3 } & Living with partner & 8.3 \\
\cline { 2 - 3 } & Divorced & 5.7 \\
\cline { 2 - 3 } & Widowed & 5.0 \\
\hline \multirow{5}{*}{ Residence } & Urban & 75.2 \\
\cline { 2 - 3 } & Suburban & 24.8 \\
\hline Age & North & 38.1 \\
\cline { 2 - 3 } & Central & 43.4 \\
\cline { 2 - 3 } & South & 18.4 \\
\hline & $<=25$ & 16.8 \\
\cline { 2 - 3 } & $26-35$ & 17.5 \\
\cline { 2 - 3 } & $36-45$ & 17.0 \\
\cline { 2 - 3 } & $46-65$ & 30.7 \\
\hline & $=>66$ & 18.0 \\
\hline
\end{tabular}

scores for Connectedness to Nature for respondents in Northern, Central and Southern Italy, and for rural and urban respondents, respectively.

Analysis of variance (ANOVA) revealed

significant differences in scores for Connectedness to Nature as a function of geographical context $\left(\mathrm{F}_{[2,1051]}=9.15 ; \mathrm{p}<0.001\right)$ : the respondents from Central Italy produced the highest scores (3.9 \pm 0.84$)$,

Tab. 2 - Descriptive statistics of the main variables measured in the survey. (EU): European Union; (SD): standard deviation.

\begin{tabular}{lccc}
\hline Variable & Mean & SD \\
\hline Connectedness to nature & 3.78 & 0.74 \\
\hline Estimated percentage of forest surface in own region & 46.7 & 19.7 \\
\hline Estimated percentage of forest surface in Italy & 46.5 & 15.5 \\
\hline Estimated percentage of forest surface in the EU & 52.4 & 16.9 \\
\hline Importance of the issue of climate change & 4.49 & 0.79 \\
\hline Importance of the issue of desertification & 4.19 & 0.91 \\
\hline Importance of the issue of biodiversity protection & 4.44 & 0.75 \\
\hline Importance of the issue of wood/cellulose/biomass production & 3.84 & 0.97 \\
\hline Importance of the issue of support for tourism & 3.89 & 1.06 \\
\hline Importance of forests for climate change & 4.52 & 0.73 \\
\hline Importance of forests for desertification & 4.26 & 0.92 \\
\hline Importance of forests for biodiversity protection & 4.47 & 0.75 \\
\hline Importance of forests for wood/cellulose/biomass production & 4.24 & 0.91 \\
\hline Importance of forests for support for tourism & 3.83 & 1.03 \\
\hline Importance of firewood & 3.42 & 1.14 \\
\hline Importance of construction wood & 3.66 & 1.00 \\
\hline Importance of biomass/cellulose & 3.62 & 0.93 \\
\hline Importance of wild berries/mushrooms/fruits & 3.75 & 1.03 \\
\hline Importance of medicines and nutraceuticals & 3.91 & 0.99 \\
\hline Importance of health and well-being & 4.22 & 0.88 \\
\hline Importance of social cohesion and sense of community & 3.68 & 1.10 \\
\hline Importance of environmental education & 4.33 & 0.84 \\
\hline It is necessary that human beings take care of forests & 4.17 & 1.05 \\
\hline Forests must be left free from human interference & 3.08 & 1.31 \\
\hline
\end{tabular}




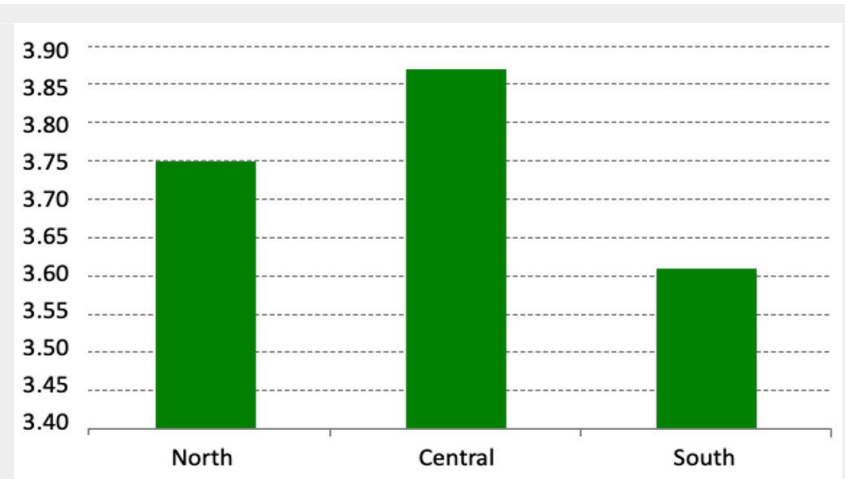

Fig. 1 - Connectedness to Nature scores of respondents across North, Central, and South Italy.

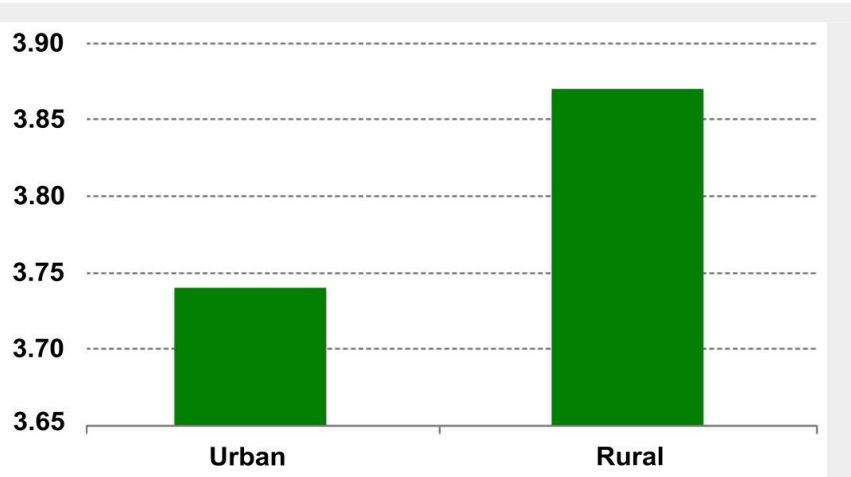

Fig. 2 - Connectedness to Nature scores of urban and rural residents. those from Southern Italy $(3.6 \pm 0.63)$ the lowest and those from Northern Italy are in between $(3.7 \pm 0.64)$. Also, rural residents exhibited significantly higher $\left(F_{[1,1048]}=5.98\right.$; $\mathrm{p}<0.05)$ Connectedness to Nature scores $(3.9 \pm 0.73)$ compared to urban residents $(3.7 \pm 0.74)$.

We also examined the correlations between the Connectedness to Nature scores and the main variables included in the questionnaire. Overall, the CNS scores showed an interesting pattern of significant positive correlations with the other variables, although the size of these correlation is small-to-medium. Connectedness to Nature was positively correlated to the perceived extension of forests in the region (Pearson's $\mathrm{r}=0.086 ; \mathrm{p}=0.005 ; \mathrm{N}=$ 1052). More interestingly, CNS scores were also positively correlated to the perceived importance of forests for sports, relaxation and illness prevention $(r=0.304 ; p<0.001$; $\mathrm{N}=1047$ ) and to the perceived importance of forests for social cohesion and community identity $(r=0.245 ; p<0.001 ; N=1045)$. Lastly, CNS scores emerged as positively correlated to participants' perceived importance of biodiversity conservation as a general environmental issue $(r=0.285 ; p<$ $0.001 ; N=1049$ ) and to the perception of forests as a useful tool for biodiversity protection $(r=0.288 ; p<0.001 ; N=1045)$.

\section{Perceptions of forest surface extension} and beliefs about forest management With regard to participants' perception of forest extension (Fig. 3, Fig. 4), results show a generalized tendency to overestimate the percentage of forest surface cover in their own region, country, and in the $\mathrm{EU}$, independently of region of residence. In general, participants expressed a positive opinion about the need for human intervention in forest management. As reported in Tab. 2, the average score in this item was 4.17 on a scale ranging from 1 to 5. However, this opinion varied significantly across the different geographical regions $\left(\mathrm{F}_{[2,1057]}=3.69 ; \mathrm{p}<0.05\right)$. Participants from Central Italy yielded the highest scores in terms of need of human intervention (4.27), while participants from Northern Italy produced the lowest (4.08).

\section{Beliefs about general environmental} issues and importance of forests

Lastly, we explored participants' beliefs about the importance of forests to address a number of environmental issues, and about the importance of different material and non-material products and services related to forests for human benefit. All the major environmental issues listed in our questionnaire were judged as rather important by respondents, with average scores above 3.5 for all the items, where 3 was the middle point on the response scale. Fig. 5 shows the average scores for each of the environmental issues. Climate change was judged as the most important issue, while wood/biomass production was judged as the least important. Likewise, when asked about the ability of forests to tackle each of these major environmental issues, respondents registered high scores (>3.5). Again, climate change was judged as the environmental issue for which forests could play the most important positive role.

We then analyzed the perceived importance of forests to produce different material goods and non-material services for human society. Forests were judged as highly important for each of the goods/services listed, with average scores above 3. Interestingly, however, some differences emerged in relation to participants' geographical region of residence (North-Central-South), especially for the more "social" goods and services such as social cohesion and sense of community, environmental education, health and well-being, and production of medicines and nutraceuticals. With regard to social cohesion and sense of community $\left(\mathrm{F}_{[2,1046]}=11.26 ; \mathrm{p}<0.001\right)$, and environmental education $\left(\mathrm{F}_{[2,1047]}=\right.$ 11.52; $p<0.001)$, the highest importance

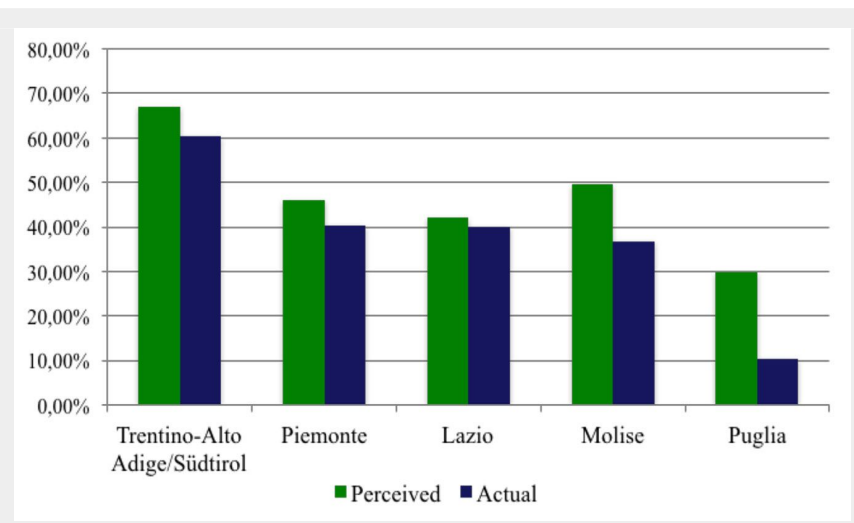

Fig. 3 - Perception of forest surface cover in participants' own region.

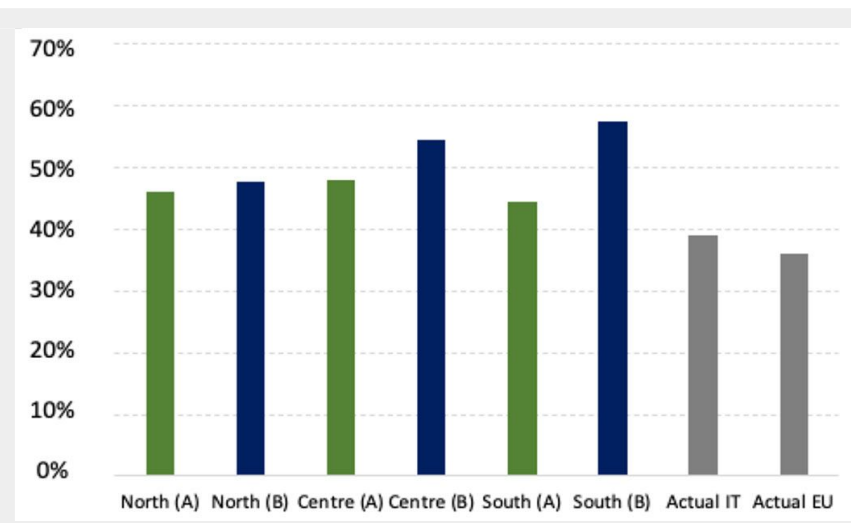

Fig. 4 - Perception of forest surface in Italy (A) and the entire EU (B) across respondents' geographical regions. 
was attributed to forests by residents of Southern Italy, while less importance was attributed by people living in Northern and Central Italy. The importance attributed to forests for the promotion of social cohesion also varied as a function of urban-rural residence, with higher importance scores expressed by rural participants $\left(\mathrm{F}_{[1,1045]}=\right.$ 3.85; $p=0.05)$. On the contrary, concerning health and well-being $\left(\mathrm{F}_{[2,1049]}=56.41 ; \mathrm{p}<\right.$ 0.001 ) and the production of medicines and nutraceuticals $\left(\mathrm{F}_{[2,1048]}=12.31 ; \mathrm{p}<\right.$ 0.001), the highest importance was attributed to forests by residents of Central Italy in comparison to people living in Northern and Southern Italy.

\section{Discussion and conclusions}

In this study, we aimed at exploring the perceptions of forests among the general public in Italy through a self-reported survey. We began from the assumption, which is generally shared in the scientific community in forestry and environmental science, that forests play a crucial role for ensuring ecosystem function and quality of environment on the planet for humans and nonhuman species. Our approach is also based on the extensive body of literature, developed in environmental psychology and other social and behavioral science disciplines, regarding the positive role of forests and contact with nature and green spaces for human health and well-being (Nilsson et al. 2011). It is therefore important to assess and monitor people's perceptions, attitudes and beliefs in relation to forests. In fact, understanding the views of the public opinion on forests, as well as on other relevant environmental and ecological issues, provides relevant information that could offer useful insights to scientists, practitioners and decision makers in the environmental domain (Bain et al. 2019).

Our work is also based on theories on the social construction of human relations to the natural world and relevant environmental issues (Graumann \& Kruse 1990, Carrus et al. 2009, Pol et al. 2006). Understanding these processes of representation, attribution of psychological and cultural meaning, and valuation is crucial if we wish to promote citizenship awareness and a more participated management of environmental resources and territories.

Interestingly, our results confirm that an accurate correspondence between objective and subjective indicators of human relationships to the relevant environmental aspects of their lives should not be taken for granted, as many studies on the differences between experts' and laypersons' assessments of environmental issues and quality have frequently reported (Sanesi et al. 2006). Respondents to our survey showed a generalized tendency to overestimate forest surface area not only in their own and more immediate surroundings (e.g., region) but also in their whole country and the entire EU. These findings

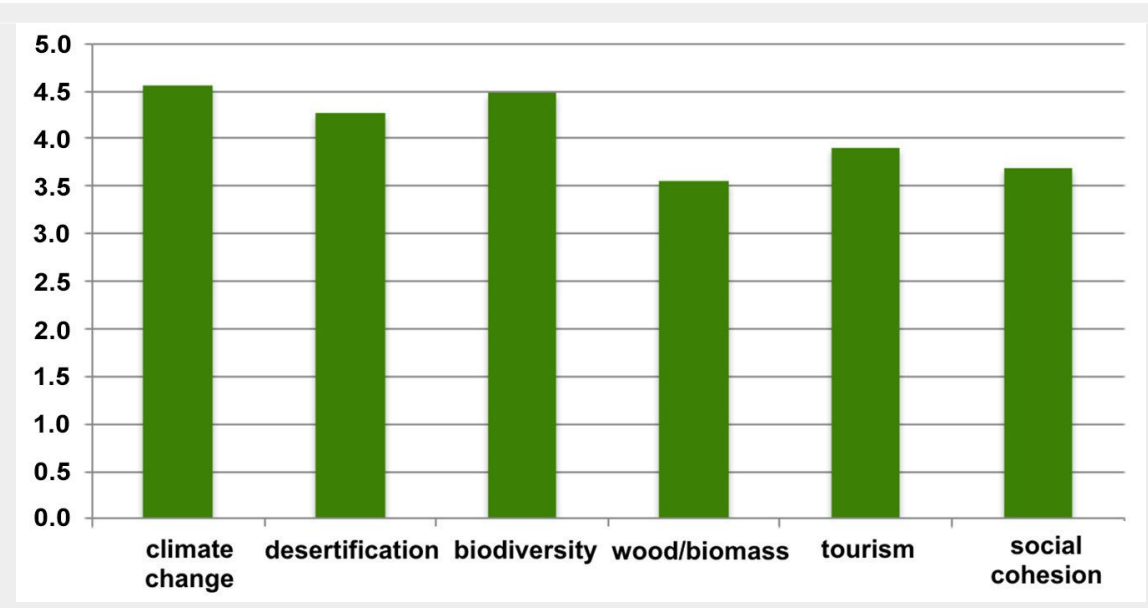

Fig. 5 - Perceptions of importance attributed to major environmental issues.

should lead us to focus more heavily on the need to communicate facts and numbers regarding forests in Italy to enhance public knowledge. One can argue that overestimating the presence of forests could lead people to underestimate their crucial role in the functioning and quality of ecosystems as well as the quality of human life. Indeed, a negative correlation emerged from our data between the estimated percentage of forest surface area and the perceived importance of forests for the protection of biodiversity (Pearson's $r=-0.07$; $\mathrm{p}=0.03 ; \mathrm{N}=1056$ ). However, since the pattern of this correlation is not so distinct, this issue deserves further investigation in future studies.

An interesting theme stemming from our findings is also connected to the perceived importance of major environmental issues and on the perceived importance of forests for tackling such issues. Although we detected some interesting variations in relation to the different geographical contexts where the respondents live, the overall picture is one of generalized high scores given to these items. This pattern suggests that while there might still be some public uncertainty on the quantitative aspects that characterize public perception of forests in Italy, there is enough public awareness on the important function of forests in present-day society. Again, this result is in line with empirical research carried out extensively in the last three decades within many different disciplinary fields, such as environmental psychology, urban forestry or landscape ecology, showing how people is increasingly aware of the ecological and social values of forest and trees in contemporary society (Nilsson et al. 2011). In fact, respondents to our survey do share the perception that forests have a crucial value for a wide number of human needs and activities, including the less material ones, although they tend to overestimate the extension of forest surfaces in Italy and the EU. Interestingly, our findings also show how Connectedness to Nature could be a psychological factor that positively pre- dicts individuals' perception of the importance of global environmental issues, and of the importance of forests to tackle complex global challenges such as biodiversity protection, as well as the positive role of forests for health promotion and social cohesion. An interesting issue for future research could be to ascertain to what extent the public perceptions and evaluation of forests is also linked to automatic and unconscious processes, as it has been already suggested for nature in particular (Schultz et al. 2004) and for other aesthetic judgments in general (Mastandrea et al. 2011, Mastandrea \& Maricchiolo 2014).

Some limits of our study must be acknowledged. In fact, although we dealt with a considerable sample size and took care of recruiting respondents in Northern, Central and Southern Italy, and in both urban and rural areas, we did not adopt a national representative sample. Thus, to generalize our results to the entire Italian population would require further corroboration through more robust sampling.

In conclusion, the present findings could represent a starting point for a deeper understanding of how forests are perceived and represented at the level of general public opinion in Italy. In addition, these perceptions and representations could provide useful information to develop better strategies for the transition to sustainability and the pursuit of more sustainable lifestyles among the Italian population.

\section{Acknowledgments}

This study was funded by Società Italiana di Selvicoltura e Ecologia Forestale (SISEF).

Individual contributions of authors: GC wrote the main text, AP performed the statistical analysis and contributed to write the results section, JIA, MM, RM, GT and GS contributed to write and review the main text. GS, AP and GC supervised the data collection process.

\section{References}

Abel T (1998). Complex adaptive systems, evolutionism, and ecology within anthropology: in- 
terdisciplinary research for understanding cultural and ecological dynamics. Journal of Ecological Anthropology 2: 6-29. - doi: 10.5038/21 62-4593.2.1.1

Bain PG, Kroonenberg PM, Johansson LO, Milfont TL, Crimston CR, Kurz T, Bushina E, Calligaro C, Demarque C, Guan Y, Park J (2019). Public views of the Sustainable Development Goals across countries. Nature Sustainability 2 (9): 819-825. - doi: 10.1038/s41893-019-0365-4 Carrus G, Cini F, Bonaiuto M, Mauro A (2009). Local mass media communication and environmental disputes: an analysis of press communication on the designation of the Tuscan Archipelago National Park in Italy. Society and Natural Resources 22: 607-624. - doi: 10.1080/08941 920802112734

Carrus G, Passiatore Y, Pirchio S, Scopelliti M (2015a). Contact with nature in educational settings might help cognitive functioning and promote positive social behaviour. PsyEcology 6: 191-212. - doi: 10.1080/21711976.2015.1026079 Carrus G, Scopelliti M, Lafortezza R, Colangelo G, Ferrini F, Salbitano F, Agrimi M, Portoghesi L, Semenzato P, Sanesi G (2015b). Go greener, feel better? The positive effects of biodiversity on the well-being of individuals visiting urban and peri-urban green areas. Landscape and Urban Planning 134: 221-228. - doi: 10.1016/j.land urbplan.2014.10.022

Carrus G, Scopelliti M, Panno A, Lafortezza R, Colangelo G, Pirchio S, Ferrini F, Salbitano F, Agrimi M, Portoghesi L, Semenzato P, Sanesi G (2017). A different way to stay in touch with "urban nature": the perceived restorative qualities of botanical gardens. Frontiers in Psychology, 8. - doi: 10.3389/fpsyg.2017.00914

Frantzeskaki N, Dumitru A, Anguelovski I, Avelino $F$, Bach M, Best B, Binder C, Barnes J, Carrus $G$, Egermann $M$, Haxeltine A, Moore M, Garcia Mira R, Loorbach D, Uzzell D, Omann I, Olsson P, Silvestri G, Stedman R, Wittmayer J, Durrant $R$, Rauschmayer $F$ (2016). Elucidating the changing roles of civil society in urban sustainability transitions. Current Opinion in Environmental Sustainability 22: 41-50. - doi: 10.1016/j.co sust.2017.04.008

Graumann C, Kruse L (1990). The environment: social construction and psychological problems. In: "Societal Psychology" (Himmtelweit HT, Gaskell G eds). Sage, London, UK, pp. 212229. [online] URL: http://psycnet.apa.org/reco rd/1990-97706-010

Hartig T, Van Den Berg AE, Hagerhall CM, Tomalak M, Bauer N, Hansmann R, Ojala A, Syngollitou E, Carrus G, Van Herzele H, Bell S, Camilleri Podesta MT, Waaseth G (2011). Health benefits of nature experience: psychological, social and cultural processes. In "Forests, Trees and Human Health" (Nilsson K, Sangster M, Gallis C, Hartig T, De Vries S, Seeland K, Schipperijn J eds). Springer, Dordrecht, The Netherlands, pp. 127-168. - doi: 10.1007/978-90-481-9806-1_5 Heberlein T (1989). Attitudes and environmental management. Journal of Social Issues 1: 37-57. doi: 10.1111/j.1540-4560.1989.tb01532.x

IUTI (2017). Italian inventory of land use. Ministero dell'Ambiente e della Tutela del Territorio e del Mare, Roma, Italy. [in Italian] [online] URL: http://www.pcn.minambiente.it/geoport al/catalog/search/resource/details.page?uuid= \{96BDDF44-8729-4F55-815F-6ECC78B6D30A\} Marchetti M, Motta R, Pettenella D, Sallustio L, Vacchiano G (2018). Forests and the forestwood system in Italy: towards a new strategy to respond to internal and global challenges. Forest@ 15: 41-50. [in Italian with English abstract ] - doi: 10.3832/efor2796-015

Mastandrea S, Bartoli G, Carrus G (2011). The automatic aesthetic evaluation of different art and architectural styles. Psychology of Aesthetics, Creativity, and the Arts 5: 126-134. - doi: 10.1037/aoo21126

Mastandrea S, Maricchiolo F (2014). Implicit and explicit aesthetic evaluation of design objects. Art and Perception 2: 141-162. - doi: 10.1163/221 34913-00002015

Mayer FS, Frantz CM (2004). The connectedness to nature scale: a measure of individuals' feeling in community with nature. Journal of Environmental Psychology 24: 503-515. - doi: 10.1016 /j.jenvp.2004.10.001

Mayer FS, Frantz CM, Bruehlman-Senecal E, Dolliver $L$ (2009). Why is nature beneficial. Environment and Behavior 41: 607-643. - doi: 10.1177/ 0013916508319745

Meijaard E, Abram NK, Wells JA, Pellier AS, Ancrenaz M, Gaveau DL, Runting RK, Mengersen K (2013). People's perceptions about the importance of forests on Borneo. PLoS One 8: e73008. - doi: 10.1371/journal.pone.0073008

Mercado-Doménech SJ, Carrus G, Terán-AlvarezDel-Rey A, Pirchio S (2017). Valuation theory: an environmental, developmental and evolutionary psychological approach. Implications for the field of environmental education. Journal of Educational, Cultural and Psychological Studies (ECPS) 16: 77-97. - doi: 10.7358/ecps-2017016-merc

Navarro O, Tapia-Fonllem C, Fraijo-Sing B, Roussi $N$, Ortiz-Valdez A, Guillard M, Wittenberg I, Fleury-Bahi G (2019). Connectedness to nature and its relationship with spirituality, wellbeing and sustainable behaviour. Psyecology 11: 3748. - doi: 10.1080/21711976.2019.1643662

Nilsson K, Sangster M, Gallis C, Hartig T, De Vries S, Seeland K, Schipperijn J (2011). Forests, trees and human health. Springer, Dordrecht, The Netherlands, pp. 427. - doi: 10.1007/978-90-4819806-1

Paletto A, De Meo I, Cantiani P, Guerrini S, Lagomarsino A (2018). Social perception of forest management: the case of the peri-urban forest of Monte Morello (Florence, Italy). Forest@ 15: 29-39. [in Italian with English abstract] - doi: 10.3832/efor2769-015

Panno A, Carrus G, Lafortezza R, Mariani L, Sanesi $G$ (2017). Nature-based solutions to promote human resilience and wellbeing in cities during increasingly hot summers. Environmental Research 159: 249-256. - doi: 10.1016/j.envres.2017. 08.016

Pasca L, Aragonés JI, Fraijo-Sing B (2019). Categorizing landscapes: Approaching the concept of Nature / Categorizando paisajes: una aproximación al concepto de naturaleza. PsyEcology 6: 1-21. - doi: 10.1080/21711976.2019.1659029

Pastorella F, Maesano M, Paletto A, Giacovelli G, Vivona S, Veltri A, Pellicone G, Matteucci G, Scarascia Mugnozza G (2017). Ecosystem services in forests of Calabria: stakeholders' perception. Forest@ 14: 143-161. [in Italian with English abstract] - doi: 10.3832/efor2219-014 Perlin J (1991). A forest journey: the role of wood in the development of civilization. Harvard University Press, Cambridge, USA, pp. 446.

Pol E, Castrechini A, Carrus G (2017). Quality of life and sustainability: the end of quality at any price. In "Handbook of Environmental Psychology and Quality of Life Research" (Fleury-Bahi G, Pol E, Navarro O eds). Springer International, Cham, Switzerland, pp. 11-39.

Pol E, Di Masso A, Castrechini A, Bonet M, Vidal T (2006). Psychological parameters to understand and manage the NIMBY effect. Revue Européenne de Psychologie Appliquée/European Review of Applied Psychology 56: 43-51. - doi: 10.1016/j.erap.2005.02.009

Roovers P, Hermy M, Gulinck H (2002). Visitor profile, perceptions and expectations in forests from a gradient of increasing urbanisation in central Belgium. Landscape and Urban Planning 59: 129-145. - doi: 10.1016/S0169-2046(02) 00011-7

Sanesi G, Lafortezza R, Bonnes M, Carrus G (2006). Comparison of two different approaches for assessing the psychological and social dimensions of green spaces. Urban Forestry and Urban Greening 5: 121-129. - doi: 10.1016/j.ufug.2006.06.001

Schultz PW, Shriver C, Tabanico JJ, Khazian AM (2004). Implicit connections with nature. Journal of Environmental Psychology 24: 31-42. doi: 10.1016/S0272-4944(03)00022-7

Tam K (2013). Concepts and measures related to connection to nature: similarities and differences. Journal of Environmental Psychology 34: 68-78. - doi: 10.1016/j.jenvp.2013.01.004

Van Den Berg AE, Hartig T, Staats H (2007). Preference for nature in urbanized societies: stress, restoration, and the pursuit of sustainability. Journal of Social Issues 63: 79-96. - doi: 10.1111/j. 1540-4560.2007.00497.x 